\title{
Some structural determinants of melody recall
}

\author{
MARILYN BOLTZ \\ Haverford College, Haverford, Pennsylvania
}

\begin{abstract}
Sophisticated musicians were asked to recall, using musical notation, a set of unfamiliar folk tunes that varied in rhythmic structure and referents of tonality. The results showed that memory was facilitated by tonic triad members marking phrase endings, but only when their presence was highlighted by a corresponding pattern of temporal accents. Conversely, recall significantly declined when tonal information was either absent or obscured by rhythmic structure. Error analyses further revealed that the retention of overall pitch contour and information at phrase ending points varied as a function of these manipulations. The results are discussed in terms of a framework that links the acts of perceiving and remembering to a common attentional scheme.
\end{abstract}

Psychomusicologists have long sought to determine how music is represented in memory and subsequently used for both the perception and production of musical events. Much of this research, however, has relied on recognition memory techniques to assess the role of contour (e.g., Dowling, 1978; Dowling \& Fujitani, 1971; Edworthy, 1983), chroma (e.g., Dowling, 1982; Kallman \& Massaro, 1979), and rhythmic structure (e.g., Jones, Boltz, \& Kidd, 1982; Kidd, Boltz, \& Jones 1984; Monahan, Kendall, \& Carterette, 1987) on immediate memory retention. Comparatively little research has been done to investigate the recall of melodies and the structural relationships within a tune that lead to facilitated learning and long-term memorability. The purpose of the present experiment was to pursue these issues and consider the joint impact of tonal and rhythmic structure on the ability to reproduce melodies via musical notation. A secondary goal was to determine whether error analyses of recall performance reveal certain cognitive strategies in the recapitulation of a tune. Since similar relations between temporal and nontemporal information are displayed in other natural events, this research might suggest some general ways in which event structure is used during the act of remembering.

\section{Memory for Musical Events}

Many of the early studies investigating the recall of previously heard melodies were designed to test predictions from coding theory (e.g., Collard \& Povel, 1982; Restle, 1970; Simon, 1972). According to this framework, serial patterns are encoded into memory by certain mathe-

\footnotetext{
This research was supported by a Faculty Research Grant from Haverford College. The author thanks Carla van de Sande for the collection of data; Brian Knatz for assistance with the manuscript's preparation; Margaret Intons-Peterson, Robert Crowder, and two anonymous reviewers for critical comments on earlier drafts of the manuscript; and Mari R. Jones for the use of her laboratory at Ohio State University. Requests for reprints should be addressed to Marilyn Boltz, Department of Psychology, Haverford College, Haverford, PA 19041. Electronic mail address: M_BOLTZ@HVRFORD
}

matical rules relating both adjacent and nonadjacent events within a sequence. ${ }^{1}$ Some sequences are considered to be particularly simple because their underlying rule arrangement is hierarchical in nature and the recursive rewriting of rules leads to a compact memory representation. Other sequences are more complex because they either lack an underlying rule structure or can be rules combined only through a lengthy concatenation.

These assumptions have been tested in a variety of contexts (Fritzen \& Johnson, 1969; Restle \& Brown, 1970; Rosenbaum, Kenny, \& Derr, 1983; Vitz \& Todd, 1967), but a study by Deutsch (1980) was one of the first in which their applicability to musical events was examined. In Deutsch's experiment, subjects were asked to reproduce, via musical notation, melodies that displayed either a hierarchical or no discernible rule arrangement. The results showed that performance was higher with hierarchically structured melodies, but only when the accompanying rhythm coincided with rule divisions. Recall significantly declined with incompatible segmentations and yielded accuracy levels comparable to those for unstructured sequences.

In subsequent research, Boltz and Jones (1986) extended these findings by assessing recall performance for a wider range of rule-structured melodies. Here, response protocols were examined for three types of melodies: those with a symmetrical, hierarchical as opposed to an asymmetrical, linear rule arrangement, and those with no rules at all. A special feature of these studies was the careful assessment of the relative impact of melodic contour. The results indicated that higher order rule arrangement was less important for melody recall than were the number and relative timing of contour changes within a tune (i.e., changes in pitch direction). Although rule-generated melodies were clearly easier to recall than no-rule melodies, differences between hierarchical and linear patterns were strictly due to changes in pitch contour and unrelated to any theoretical constructs of code complexity.

In sum, applications of coding theory to the encoding and subsequent remembering of musical events have encountered limited success. The applicability of coding the- 
ory is cast into further doubt in that most Western music is not composed from a set of strict mathematical rules. Instead, melodies typically traverse a more creative path, along which changes in pitch and harmony are artfully interwoven with changes in timbre, loudness, and relative timing. Thus, to fully understand the memorial representation of musical events, research involving more naturalistic types of musical stimuli is needed.

Unfortunately, such studies are notably absent from the psychological literature. Although several experiments have investigated memory recall of visually presented musical scores (Halpern \& Bower, 1982; Sloboda, 1976, 1978), very few have addressed how listeners reproduce previously heard compositions from long-term memory. An exception is an observational study by Sloboda and Parker (1985). Presented with folk tunes as musical stimuli, a group of four musicians and nonmusicians were asked to reproduce each tune by singing. Response protocols were then analyzed on a variety of structural dimensions to determine which aspects of a melody were best remembered after this one trial learning period. Results showed that meter was one of the most enduring invariants, in that almost all protocols preserved the original metrical structure of a tune. Melodic phrasing was also well preserved, in that most subjects displayed audible breaths at phrase boundaries and remembered the temporal ordering of phrases that were either novel or repeats of earlier ones. Other features of the melodies' structures, including overall pitch contour, rhythm, and harmonic progressions, were remembered less well and yielded wide variability among individual subjects.

This seminal study on melody recall is important because it reveals some structural relations that remain prominent in memory during the initial stages of perceptual learning. As Sloboda and Parker acknowledge, however, their study also raises a host of questions. The most obvious one concerns the underlying cognitive processes guiding retrieval and the precise role of certain melodic features in the recapitulation of a tune. Although meter and melodic phrasing are both well remembered after a single exposure to a tune, it is not clear whether this is due to perceptual salience or because they are critically important for the act of remembering. If they are important for memory retrieval, why is this so from a cognitive perspective, and exactly how are they used to organize and subsequently recapture a melody's overall sequence of notes?

The purpose of the present research was to investigate these issues by systematically manipulating both the relative timing and the melodic phrase structure of musical events within a recall task. The primary intent was to extend the work of Sloboda and Parker (1985) by examining the role of tonal information within melodic phrases, and whether a joint accent structure of melodic and temporal information might serve to guide the perceptual pickup and subsequent remembering of a tune.

\section{Melodic Phrase Structure}

Most musical theorists agree that the underlying organization of a tune derives from its tonality scheme. Tonality refers to the underlying scale in which a melody is written, which in turn constrains what particular notes will appear in a melody and how they are ordered in time. For example, a melody may be written in the key of $\mathrm{C}$ major, indicating that its tonal intervals are derived from the $\mathrm{C}$ major diatonic scale. Since tonality provides a stable, unifying framework for a melody, several people have suggested that listeners initially attempt to extract the underlying key of a tune and then relate subsequent intervals to this tonality scheme. To a large extent, tonality can be inferred from the use of tonic triad members that mark certain structural relations within a tune. The tonic refers to the underlying key in which a melody is written (e.g., C for a melody in the key of $\mathrm{C}$ major), and together with the dominant $(\mathrm{G})$ and the mediant $(\mathrm{E})$, these three intervals form the melody's major chord, the tonic triad. One nonarbitrary use of these intervals involves tonal resolution, wherein the ending of a melody is marked by a prolonged tonic (Boltz, 1989a, 1989b; Kramer, 1982; Meyer, 1956). By returning a listener to the tonal base in which a melody is written, music conveys a psychological sense of closure.

A second common convention is to mark phrase endings with tonic triad members (Berry, 1976; Cone, 1968; Piston, 1978; Todd, 1985). Consider, for example, the folk tune depicted in Figure 1. This melody is written in the key of $F$ major, and it resolves on the tonic note, F. Within this total time span, sequences of notes are nested within four melodic phrases, with the ending of each marked by the dominant, mediant, mediant, and tonic, respectively. One psychological consequence of this convention is that phrase ending points provide a sense of stability and resolution within a tune by reaffirming the underlying tonality scheme. Another important function is to attentionally highlight a melody's hierarchical structure. That is, the beginnings and ends of melodic phrases often recur with temporal regularity to outline nested levels of melodic structure (Deutsch \& Feroe, 1981; Jones \& Boltz, 1989; Lerdahl \& Jackendoff, 1983). The folk tune shown in Figure 1, for example, displays melodic phrases that recur after every 6 beats, which in turn are nested within higher order melodic spans of 12 beats. Tonic triad members marking phrase ending points, whose prominence is often enhanced by coaccompanying pitch skips and/or contour changes (Benjamin, 1984; Berry, 1976; Jones, 1987; Thomassen, 1982), thus serve to reveal a melody's overall organization and relations among both adjacent and nonadjacent notes.

The previous literature indicates that tonality does influence memory performance. Using a recognition memory task, Cuddy, Cohen, and Mewhort (1981) found that performance significantly declines when melodies contain increasingly less tonal information (i.e., elimination of 

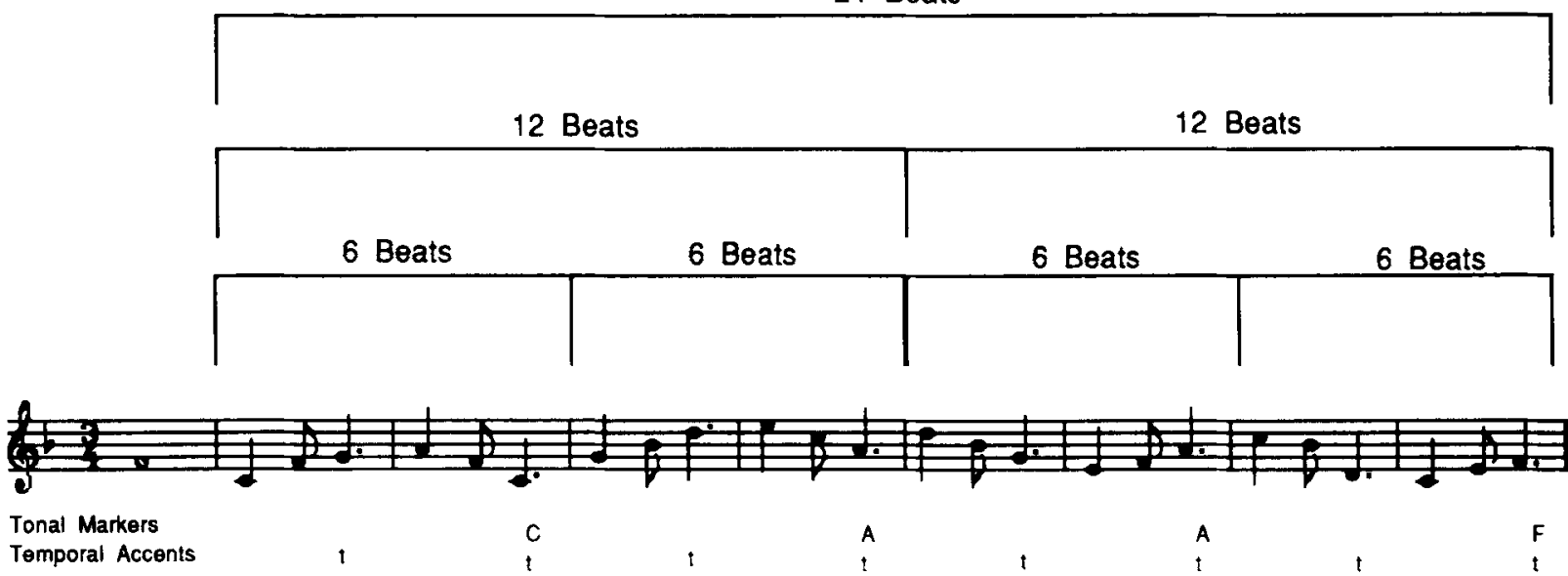

Figure 1. Example of a musical composition displaying a hierarchical arrangement of melodic/temporal structure. This melody opens and closes on the tonic note, $F$, and thereby displays tonal resolution. Within this total time span, sequences of notes are nested within four melodic phrases marked by tonic triad members (the dominant, mediant, mediant, and tonic, respectively). Phrase endings are attentionally highlighted by temporal accents $(\mathrm{d})$, and both regularly recur in time to outline higher order phrase relationships.

a I V I chord progression and the insertion of atonal notes, respectively), while Cuddy, Cohen, and Miller (1979) found that melodies ending on the tonic are more accurately recognized than ones ending with a random sequence of diatonic notes. Lastly, when subjects are asked to remember the location of clicks superimposed on an ongoing melody, these locations are often misremembered as being melodic phrase boundaries (Sloboda \& Gregory, 1980).

Although the effects of tonality on memory recall have not been extensively investigated, some research does show that children are better able to reproduce rhythmic sequences if tonic triad members are present to mark melodic phrase endings (Gerard \& Auxiette, 1988). Such findings may also apply to the recall of a melody's sequence of notes. Since tonal markers of phrase endings are intimately tied to the underlying tonality scheme, they afford potential anchors or reference points for remembering. Their retrieval outlines the underlying melodic organization and thereby provides a scheme in which to recapitulate the overall sequence of notes. As noted by Deutsch and Feroe (1981), notes within a given phrase tend to be grouped by similarities in pitch and contour which may facilitate retrieval at this lowest level.

One aim of the present study was to test these ideas by asking musically sophisticated listeners to recall unfamiliar folk tunes whose phrase endings were either marked by tonic triad members or some other in-key intervals. The prediction was that if tonal markers do act as effective anchors, recall should be significantly higher with their presence and should markedly decline with their absence. Subsequent analyses of errors should also reveal whether recall is more successful at phrase ending points and whether errors can be predicted from the underlying tonality scheme.

\section{Rhythm and Temporal Accent Structure}

A second goal was to examine the impact of temporal accent structure on melody recall. Music displays a number of lawful temporal relationships, but the most common characterizations are in terms of meter and rhythm. Meter refers to the underlying beat of a melody and the grouping of beats within a mensural framework. For example, the tune shown in Figure 1 is written in a 3/4 meter, indicating that a quarter note $(d)$ is the referent beat and that each measure contains three beats of time. Within this metrical backdrop, rhythm imparts a series of durational changes such that some notes receive relatively more (e.g., dotted quarter notes, d.) or fewer (e.g., eighth notes, $\delta$ ) beats than the referent beat. Rhythm is considered to be psychologically important because prolonged tonal durations and pauses give rise to temporal accents that "stand out" and capture a listener's attention. In much of Western music, these temporal accents recur with an invariant periodicity and coincide with melodic phrase endings to yield a joint melodic/temporal accent structure (Boltz \& Jones, 1986; Jones \& Boltz, 1989; Lerdahl \& Jackendoff, 1983; Monahan \& Carterette, 1985; Yeston, 1976). Notice that in Figure 1 temporal accents $(t)$ recur after every 6 beats and thereby reinforce tonic triad members that mark phrase boundaries.

The effects of a joint accent structure on cognitive behavior are well documented within the psychological literature. One function is to provide a structural basis for anticipatory attending and the generation of expectancies. 
Since joint accents tend to recur with temporal regularity, a listener is not only able to anticipate the "what" of upcoming accents but also "when" they should occur (Jones 1976, 1981a, 1981b; Jones \& Boltz, 1989). The confirmation/violation of these expectancies, in turn, have been found to influence the detection of deviant notes within a melody (Dowling, Lund, \& Herrbold, 1987; Jones, et al., 1982; Monahan, et al., 1987), ratings of tonal resolution (Boltz, 1989a, 1989b) and tension (Povel, 1985 ), and the accuracy of relative duration judgments (Boltz, 1985, 1989c; Jones \& Boltz, 1989). In addition to guiding dynamic attending, joint accent structures serve a second important function-namely, to highlight an event's nontemporal organization and relations among multiple levels of structure. Evidence for this idea has been demonstrated with a variety of stimuli, including series of digits and letters (Bower \& Springston, 1970; Bower \& Winsenz, 1969), sequences of lights (Restle, 1972), simple auditory patterns (Handel, 1973, 1974), and linguistic material (Butterworth, 1975; Goldman-Eisler, 1968; Martin, 1972). With respect to music-like patterns, both Deutsch (1980) and Boltz and Jones (1986) have investigated the effects of melodic/temporal accent structure on recall performance. The stimuli used in these experiments were designed to test predictions of coding theory and displayed tonal groups (of 3 to 4 notes) related through certain mathematical rules (see Footnote 1). Although these melodies lacked an established tonality scheme in that tonal resolution and melodic phrasing were both absent, melodic accents arose from points of rule change and regularly recurred after every tonal group. When pauses were inserted at various locations within these tunes, the results showed that those coinciding with melodic rule breaks led to significantly higher recall than those conflicting with the underlying rule structure. Boltz and Jones (1986) subsequently interpreted these results with a "joint accent hypothesis." The basic idea is that performance depends on the ratio between the periodicity of melodic accents relative to the periodicity of temporal accents. When this ratio results in an integer value, accents are lawfully related to one another and can efficiently guide attending over the melody's time span. Noninteger values, on the other hand, will disrupt performance because the dissociation of melodic and temporal accents creates various levels of change that occur unpredictably in time. Attending is therefore misguided and fails to reveal relations among both adjacent and nonadjacent notes.

Although this model was originally proposed as a post hoc explanation of results and has never been directly tested, it does have applications for the present experiment. In lieu of mathematical rule breaks, most Western music displays melodic accents in the form of tonic triad members marking phrase ending points. If rhythm highlights these anchors of tonal organization, this should facilitate both key identification and the integration of adjacent and nonadjacent notes into a common tonal framework. An efficient retrieval scheme is provided, since the recapitulation of temporal structure will reveal tonal anchors from which to recall the entire melody. One would therefore predict that such rhythmic structures will facilitate recall relative to conditions in which temporal accents recur with an invariant periodicity but nevertheless fail to reinforce a melody's tonal organization.

These ideas were tested here by manipulating the ratio relationship between melodic and temporal accents. Specifically, the set of folk tunes used in this experiment all contain 24 notes and were originally written in a $3 / 4$ or 4/4 meter. Phrase endings occur after every other measure and thus display a 6- or 8-beat periodicity. By imposing rhythms whose temporal accents recur after 3,4 , 6 , or 8 beats, four different conditions of melodic/temporal accent structure result. In all cases, sequences of notes are parsed into temporal spans of equal size. However, in two conditions, joint accents form integer ratios such that temporal accents coincide with the endings of individual measures or melodic phrases (i.e., 3- and 6-beat rhythms for melodies based on a 3/4 meter, and 4- and 8-beat rhythms for those based on a $4 / 4$ meter, respectively). In the two remaining conditions, noninteger ratios emerge because temporal accents conflict with the hierarchical arrangement of melodic structure.

A final feature of this research was to examine the kinds of errors produced under the various temporal/ melodic conditions. In these analyses the memory for pitch information alone was assessed, since subjects were asked to reproduce melodies via musical notation. To avoid memory overloads, they were simply asked to reproduce the sequence of notes without their corresponding metric and rhythmic values. ${ }^{2}$ Accordingly, one type of error analysis involved the extent to which the melody's original contour is preserved in memory. Notes within a sequence are often grouped by a common trajectory of contour change, and joint accent structures offering tonal anchors as retrieval cues may be more successful in revealing these lawful patterns during the initial course of attending. In this case, then, pitch contour may provide another basis in which to recapitulate a melody and offer additional cues for remembering the overall sequence of notes. A second type of error analysis involved recall performance at phrase ending points. If tonic triad members act as referents for recall, these intervals should be remembered well and errors are likely to reflect confusions with other chord members. The retrieval of such intervals, of course, should be less likely with incompatible rhythms that fail to highlight their position in the melodic hierarchy.

In sum, the presence/absence of tonic triad members marking phrase ending points and the extent to which they coincide with patterns of rhythmic accent were manipulated in this experiment. The basic prediction was that compatible accent structures would provide effective retrieval schemes for melody recall. The recapitulation of metric and rhythmic structure provides a dynamic vehicle in which to recast the original course of perceiving, and the attentional highlighting of tonic triad members affords referents from which to regenerate lower order pitch 
relationships. The evidence for such a strategy should be reflected within error analyses at phrase ending points as well as more local levels of contour change. Melodies whose underlying organization is obscured by incompatible rhythms or the absence of phrase ending markers should yield significantly lower performance, since an effective scheme for perceiving and remembering is not offered within the melody's structure.

\section{METHOD}

\section{Design and Subjects}

The design was a $4 \times 2 \times 8$ repeated measures factorial. Four levels of rhythmic structure $(3,4,6$, and 8 beats) were crossed with two phrase ending types (tonal markers present or absent) and eight different folk tunes.

Sixteen undergraduate and graduate music majors were recruited from the Music Department at Ohio State University. All were proficient at music notation and had had at least 8 years of musical training within the previous 10 years. Each was paid $\$ 10$.

\section{Stimulus Materials}

A set of folk tunes from other countries was selected from a musical composition book. ${ }^{3}$ To obtain a set of eight melodies that were unfamiliar to Western listeners, a preliminary rating study was then conducted with an independent group of 12 experienced musicians. The melodies selected as experimental stimuli, depicted in Figures $2 \mathrm{~A}$ and $2 \mathrm{~B}$, represent diverse keys (C, F, or $\mathrm{G}$ major) and overall pitch contours. Nevertheless, all contain 24 notes and both open and close on the tonic note. Half of the melodies are based on a $3 / 4$ meter and half on a $4 / 4$ meter.

In their original versions, all melodies contained a tonic triad member (tonic, mediant, or dominant) that marked phrase ending points after every other measure. For those based on a $3 / 4$ meter, these phrase ending points therefore occurred after every 6 beats, and for those based on a $4 / 4$ meter, after every 8 beats. These tunes were then varied such that tonal markers of phrase ending points were replaced with other in-key intervals. As shown in Figures $2 \mathrm{~A}$ and 2B, these intervals always preserved the melody's original contour and differed from the original tonic triad member by one scale step.

For this set of 16 melodies, rhythmic structure was also varied. Four different rhythms were imposed on each melody such that agogic accents occurred after every 3rd $(\delta \delta \downarrow)$, 4th $(\delta / \delta .$.$) , 6th$

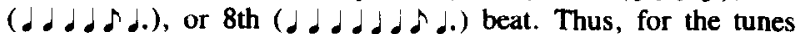
based on a $3 / 4$ meter, the rhythmic accentuation of every 3rd or 6th beat coincided with tonic triad members that marked phrase ending points, while accents falling on every 4 th or 8 th beat conflicted with the melodic phrase structure. The reverse was true for the melodies based on a 4/4 meter. Here, phrase ending points were reinforced by the 4- and 8-beat rhythms and obscured by the 3and 6-beat rhythms. Across all rhythmic conditions, tonal duration (on time) and intertone interval (off time) were held constant such that all notes corresponded to the following values: quarter notes $(\downarrow)$,

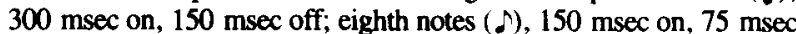
off; and dotted quarter notes ( $\mathrm{d}.), 450 \mathrm{msec}$ on, $225 \mathrm{msec}$ off.

Melodies were then randomized into four sets $\left(A_{p}, A_{a}\right.$ and $B_{p}$, $\left.B_{a}\right)$, each of which contained 32 trials. Set $A$ melodies contained four melodic instances, half based on a $3 / 4$ meter ("Oberek" and "The Rabbit and the Turtle") and half based on a $4 / 4$ meter ("The Vira" and "Lithuanian National Hymn"), presented twice under the four rhythmic conditions. The Set $A_{p}$ melodies contained versions in which tonic triad members were present to mark phrase ending points, and the Set $A_{a}$ melodies contained versions of the same tunes, in which tonic triad members were absent at phrase ending points. Set B melodies consisted of the four remaining melodic instances where once again each tune was presented twice under each of the four rhythmic variations. Lastly, two different counterbalance orders were prepared for each of the four melodic sets such that the 32 trials within each set occurred in a different random order.

\section{Apparatus}

All melodies were constructed and generated with the MIDILAB software system developed by Todd, Boltz, and Jones (1989). During an experimental session, melodies were presented on line by a Yamaha TX81Z FM tone generator controlled by an IBM-AT computer with a Roland MPU-401 MIDI interface unit. Sequences of tones were amplified by a Kenwood KR-4010 receiver and played over AKG K400 headphones at a comfortable listening level (60-65 dB). The timbre used for all melodies approximated that of a grand piano.

\section{Procedure}

Recorded instructions informed subjects of pattern presentation details and task requirements. On each trial, a 1-sec warning tone (F4) preceded a melody by $2 \mathrm{sec}$. Two seconds later, the same melody was presented a second time. During a 1.5 -min response interval, the subjects were then asked to reproduce the tune on staff paper, using musical notation. The subjects were instructed to recall only the sequence of notes for each melody (i.e., to ignore rhythm and timing) and to mark an " $\mathrm{X}$ " at locations where they failed to remember notes. Since the set of experimental melodies varied in key, the subjects were told to use the warning tone as a referent to determine whether the melody was written in the key of $C, F$, or $\mathrm{G}$ major. They were also instructed that the whole note initiating each tune corresponded to the melody's tonic. Reproduction began after the second presentation of a given melody, and a separate sheet of paper was provided for each tune to prevent the subjects from looking at previous reproductions during the course of the experiment.

One block of 32 trials was presented on each of two daily sessions, yielding a total of 64 experimental trials. Each session was approximately $1 \mathrm{~h}$ long, and a 3 -min rest break was provided after every 8 trials. Before each daily session, the subjects received 4 practice trials that consisted of a novel set of melodies in all rhythmic contexts and a given phrase ending type. The presence/absence of tonic triad members was blocked by day as was melodic instance group (Set A or B) and counterbalance order (I or II).

\section{RESULTS}

\section{Overall Error Analysis}

All melodies were initially scored for the extent to which individual notes within a sequence were correctly remembered. This was done through a first-order conditional scoring technique. Since the first note of each melody could be reliably determined from the warning tone, subsequent notes were scored correct if they preserved the correct pitch distance from the immediately preceding note. This criterion was applied regardless of whether intervals preserved or broke the melody's original contour.

Table 1 presents the mean percent total errors in melody recall as a function of joint accent structure and phrase ending type. Means are collapsed over counterbalance order, melodies based on a $3 / 4$ versus a $4 / 4$ meter, and the blocking of both melody set and presence/absence of tonic triad members, since these variables exerted no significant effects within this general analysis.

The most important finding is that melody recall depended on both the tonal markers of phrase endings and 
(A)

The Rabbit and the Turtle by G.H. Conkling

Japan

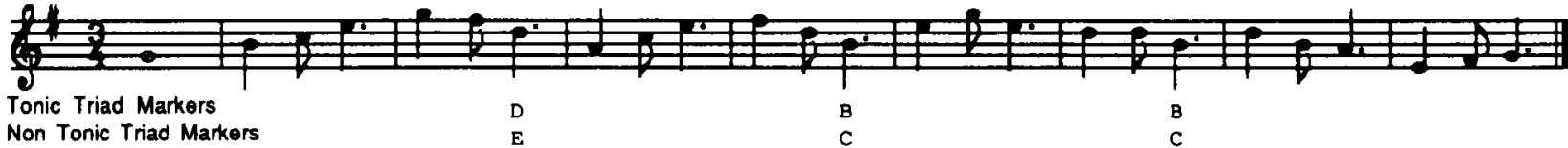

In My Dreams by C.H.B.

Lithuania

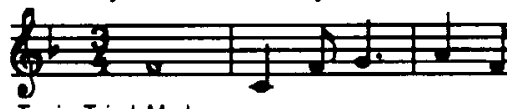

Tonic Triad Markers

Non Tonic Triad Markers

C A

B

A

Oberek by A. Guiterman

Poland

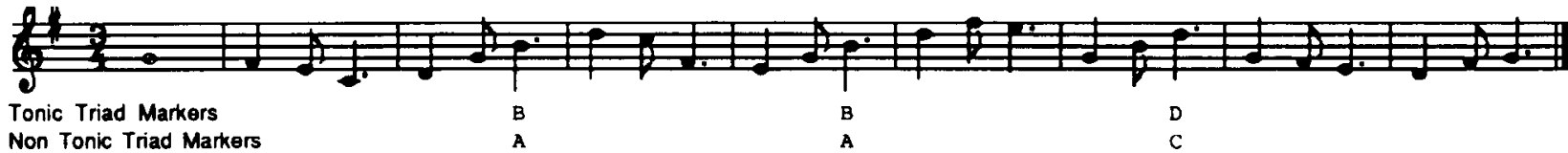

The Moon by G.H. Conkling

Japan

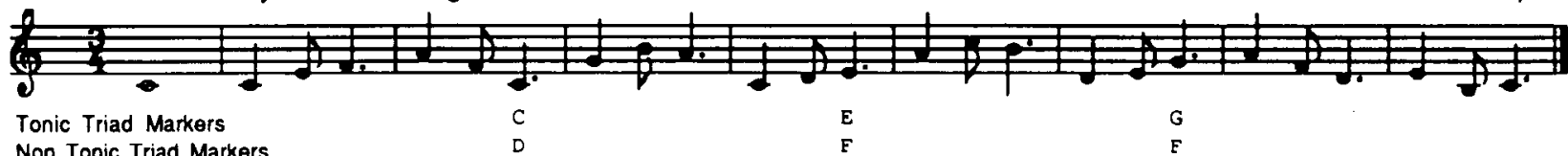

Non Tonic Triad Markers

(B)

Lithuanian National Hymn by W. Griffith

Lithuania

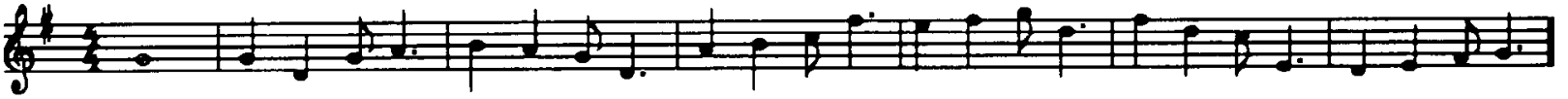

Tonic Triad Markers

Non Tonic Triad Markers

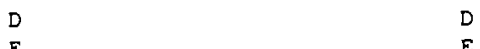

Fond Regrets by E. Markham

The Azores

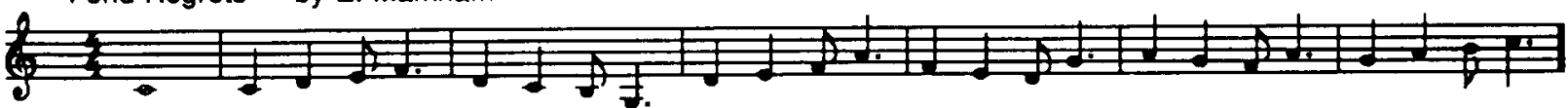

Tonic Triad Markers

Non Tonic Triad Markers

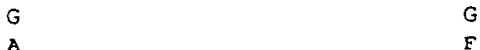

I'll Have No Other by J. Mokrejs

Czechia

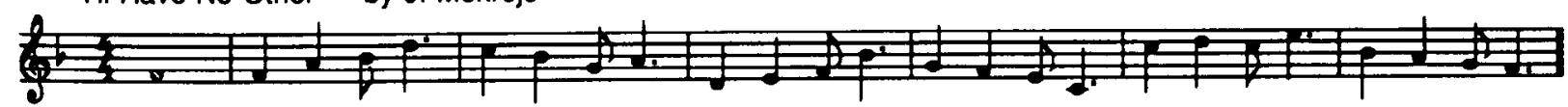

Tonic Triad Markers

Non Tonic Triad Markers

A

The Vira by A. C. Markham

Portugal

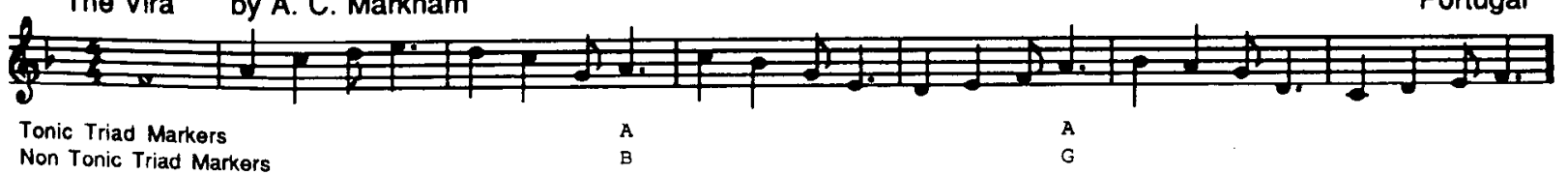

Figure 2. The set of folk tunes used as experimental stimuli. These melodies illustrate a compatible joint accent structure in that temporal accents $(d$.$) recur at the end of every measure and coincide with melodic phrases at the end of every other measure. As illustrated,$ phrase endings were marked by tonic triad members or other in-key intervals. Melodies based on a $3 / 4$ meter are depicted in panel $A$ and those based on a $4 / 4$ meter are shown in panel B. (Adapted from Folk Songs of Many Peoples, Vol. 1, edited by Florence Hudson Botsford, New York: The Woman's Press, 1921). 
Table 1

Mean Percent Total Errors in Melody Recall as a Function of Phrase Ending Type and Joint Accent Structure

\begin{tabular}{cccc} 
& \multicolumn{2}{c}{ Phrase Ending Type } & \\
\cline { 2 - 4 } Ratio & $\begin{array}{c}\text { Tonic Triad } \\
\text { Members Present }\end{array}$ & $\begin{array}{c}\text { Tonic Triad } \\
\text { Members Absent }\end{array}$ & $M$ \\
\hline & Compatible Accent Structures & \\
$8: 4$ & .41 & .61 & .51 \\
$6: 3$ & .36 & .63 & .50 \\
$8: 8$ & & & \\
$6: 6$ & Incompatible Accent Structures & .71 \\
$8: 3$ & .70 & .72 & .71 \\
$6: 4$ & & .74 & \\
$8: 6$ & .68 & .68 & \\
$6: 8$ & & & \\
$M$ & .54 & & \\
\hline
\end{tabular}

Note-Ratios refer to the periodicity of tonal markers relative to the periodicity of temporal accents.

the compatibility of rhythmic accentuation. As the row means indicate, performance was significantly higher when patterns of temporal accents coincided with the hierarchical arrangement of melodic structure than when accents "clashed" to obscure the underlying tonal organization $\left[F(3,24)=134.96, M S_{\mathrm{e}}=.021, p<.0001\right]$. Overall, recall was also higher when tonic triad members were present to outline melodic phrasing $[F(1,24)=$ $\left.59.74, M S_{\mathrm{c}}=.02, p<.0001\right]$, although this depended on the particular rhythmic structure of a melody to yield a significant interaction between these two variables $\left[F(3,24)=3.58, M S_{e}=.014, p<.03\right]$. As can be seen in Table 1, compatible accent structures yielded better performance than incompatible ones for both types of phrase endings. A set of Bonferroni post hoc comparisons $(p<.05)$ confirmed that these differences were significant for both the presence and absence of tonic triad members. In addition, recall within compatible accent conditions was significantly higher when tonic triad members were present to mark phrase endings than when phrases were marked by some other in-key intervals. This effect held for both types of compatible accent structures but did not maintain for melodies with incompatible accents. In the latter conditions, performance was uniformly low and did not vary with the presence/absence of phrase markers.

Beyond these effects of rhythm and tonality, a main effect for melodic instance $\left[F(3,24)=19.21, M S_{e}=.008\right.$, $p<.0001]$ suggests that other structural relationships within these tunes influenced melody recall. One factor involved the number of melodic phrases within a tune. As can be seen in the row means of Table 2, melodies based on a $4 / 4$ meter and containing three melodic phrases per tune were, on the average, easier to recall than those with four phrases deriving from a $3 / 4$ meter. It also appears that less difficult melodies were ones containing fewer contour changes and changes that coincided with the hierarchical arrangement of metric structure. Within the $4 / 4$ meter condition, for example, "The Vira," with six contour changes, yielded significantly higher recall than did "Fond Regrets," the "Lithuanian National Hymn," and "I'll Have No Other," with 8, 10, and 9 changes, respectively. The latter melody may have been especially difficult to remember, because more of its contour changes fail to coincide with the beginnings and ends of measures and, instead, often occur within a mensural span. Similar principles apply to tunes based on a 3/4 meter. Here, the most difficult melody ("The Moon") contains more contour changes (i.e., 9) than do the remaining three instances, and again these changes often occur in the middle of a measure. In contrast, the easiest melody within this condition ("In My Dreams") displays very lawful groupings of contour change that consistently coincide with the metrical framework.

Lastly, while these effects of melodic instance generalize to conditions of compatible accent structure, a significant interaction between melodic instance and rhythm $\left[F(9,72)=3.07, M S_{\mathrm{e}}=.003, p<.004\right]$ reveals that some tunes were more disrupted than others by incompatible accents. The simplest way to understand these effects is to note that melodies containing large pitch skips within rhythmic groups were the most difficult to recall. Table 2 indicates that for melodies based on a 3/4 meter, "The Moon" and "Oberek" yielded significantly lower performance than did either "In My Dreams" or "The Rabbit and the Turtle." These findings make sense in that 4- and 8-beat rhythms parse the latter two melodies so that large pitch skips are less apt to occur within rhythmic groups. The same principle applies to the $4 / 4$ condition where, here, the easiest tune was "The Vira." Incompatible rhythms within this melody are less apt to reveal large pitch skips within temporal segments than they are in the three other melodies.

The results of this overall analysis indicate that melody recall is most successful when patterns of temporal accents highlight groupings of notes nested within the underlying hierarchical organization of melodic structure. Individual notes can be grouped by a common trajectory of pitch contour, motion toward tonal stability, and pitch proximity, and when these changes regularly recur in time, an efficient scheme for attending and subsequent remembering is established. Memory performance declines when such changes recur with temporal unpredictability and thereby obscure the overall organization of structure.

In the next analyses, it was asked whether errors in melody recall reveal lawful patterns as a function of the experimental manipulations. Of most interest were the extent to which contour information is preserved within memory and the patterns of errors at phrase ending points. Each is addressed in turn.

\section{Memory for Contour Information}

Within this analysis, errors in melody recall were classified into one of three types: (1) the percentage of errors due to missing notes; (2) errors due to the wrong tonal interval being remembered but which nevertheless 
Table 2

Mean Percent Total Errors in Melody Recall as a Function of Melodic Instance and Joint Accent Structure

\begin{tabular}{|c|c|c|c|c|c|}
\hline \multirow[b]{3}{*}{ Melody } & \multicolumn{4}{|c|}{ Accent Structures } & \multirow[b]{3}{*}{$M$} \\
\hline & \multicolumn{2}{|c|}{ Compatible } & \multicolumn{2}{|c|}{ Incompatible } & \\
\hline & 8:4 Ratio & 8:8 Ratio & 8:3 Ratio & 8:6 Ratio & \\
\hline \multicolumn{6}{|l|}{ 4/4 Meter } \\
\hline Lithuanian National Hymn (10) & .49 & .49 & .71 & .69 & .60 \\
\hline The Vira $(6)$ & .39 & .38 & .67 & .68 & .53 \\
\hline Fond Regrets (8) & .44 & .41 & .70 & .70 & .56 \\
\hline \multirow[t]{2}{*}{ I'll Have No Other (9) } & .51 & .48 & .73 & .74 & .62 \\
\hline & 6:3 Ratio & 6:6 Ratio & 6:4 Ratio & 6:8 Ratio & \\
\hline \multicolumn{6}{|l|}{ 3/4 Meter } \\
\hline The Rabbit and the Turtle (8) & .57 & .57 & .69 & .68 & .63 \\
\hline Oberek (7) & .57 & .56 & .74 & .73 & .65 \\
\hline The Moon (9) & .59 & .59 & .77 & .80 & .69 \\
\hline In My Dreams (8) & .52 & .49 & .67 & .66 & .59 \\
\hline Means & .51 & .50 & .71 & .71 & \\
\hline
\end{tabular}

Note-Ratios refer to the periodicity of tonal markers relative to the periodicity of temporal accents. The number of contour changes within each melody is indicated within parentheses.

preserved the melody's original contour; and (3) the percentage of errors in which the misremembered tonal intervals broke or failed to match a tune's profile of contour change.

As can be seen in Table 3, error type interacts significantly with phrase ending type and joint accent structure $\left[F(6,72)=3.56, M S_{e}=.042, p<.004\right]$. When patterns of temporal accents highlighted the presence of tonal information, over $50 \%$ of the errors preserved a melody's original pitch contour. A set of Bonferroni comparisons $(p<.05)$ confirmed that this type of error was much more frequent than ones due to missing notes or intervals breaking the original contour. However, when phrase endings lacked tonal information or conflicted with a melody's rhythmic structure, a different pattern of results emerged. Here, the incidence of errors preserving contour significantly declined in all conditions, and errors due to missing notes and intervals breaking contour were much more frequent. Relative to incompatible accent structures, the preservation of contour is somewhat more apt to occur when rhythm coincides with phrases marked by other inkey intervals.

The overall analysis of variance also shows that error type varies across the different melodic instances of this experiment $\left[F(6,72)=3.12, M S_{\mathrm{e}}=.036, p<.009\right]$. To a large extent, these data are quite similar to those found within the overall error analysis discussed earlier. As can be seen in Table 4, melodies displaying fewer contour changes and changes coinciding with the underlying metrical framework are more apt to yield contour preserving errors than errors due to missing notes and intervals breaking contour. In contrast, the frequency of the latter errors increases for melodies with more contour changes and changes occurring within mensural spans.

The final effect to emerge from this analysis involves a significant interaction between error type, rhythmic structure, and the blocking by day of phrase ending type $\left[F(6,72)=3.29, M S_{\mathrm{e}}=.0465, p<.007\right]$. This finding involves asymmetrical carry-over effects such that within compatible accent structures, the frequency of con-

Table 3

Mean Percent Frequency of Each Error Type as a Function of Joint Accent Structure and Phrase Ending Type

\begin{tabular}{|c|c|c|c|c|c|}
\hline \multirow[b]{3}{*}{ Error Type } & \multicolumn{4}{|c|}{ Accent Structures } & \multirow[b]{3}{*}{$M$} \\
\hline & \multicolumn{2}{|c|}{ Compatible } & \multicolumn{2}{|c|}{ Incompatible } & \\
\hline & $\begin{array}{l}\text { 8:4 Ratio } \\
\text { 6:3 Ratio }\end{array}$ & $\begin{array}{l}\text { 8:8 Ratio } \\
\text { 6:6 Ratio }\end{array}$ & $\begin{array}{l}\text { 8:3 Ratio } \\
6: 4 \text { Ratio }\end{array}$ & $\begin{array}{l}\text { 8:6 Ratio } \\
\text { 6:8 Ratio }\end{array}$ & \\
\hline \multicolumn{6}{|c|}{ Tonic Triad Members Present } \\
\hline Missing Notes & .21 & .18 & .38 & .36 & .28 \\
\hline Contour Preserved & .52 & .55 & .25 & .27 & .40 \\
\hline Contour Broken & .22 & .24 & .35 & .33 & .29 \\
\hline \multicolumn{6}{|c|}{ Tonic Triad Members Absent } \\
\hline Missing Notes & .30 & .27 & .34 & .36 & .32 \\
\hline Contour Preserved & .36 & .37 & .29 & .29 & .33 \\
\hline Contour Broken & .28 & .31 & .34 & .33 & .32 \\
\hline
\end{tabular}


Table 4

Mean Percent Frequency of Each Error Type as a Function of Melodic Instance

\begin{tabular}{|c|c|c|c|}
\hline \multirow[b]{2}{*}{ Melody } & \multicolumn{3}{|c|}{ Error Type } \\
\hline & $\begin{array}{c}\text { Missing } \\
\text { Notes }\end{array}$ & $\begin{array}{l}\text { Contour } \\
\text { Preserved }\end{array}$ & $\begin{array}{c}\text { Contour } \\
\text { Broken }\end{array}$ \\
\hline \multicolumn{4}{|l|}{ 4/4 Meter } \\
\hline Lithuanian National Hymn (10) & .33 & .33 & .31 \\
\hline The Vira $(6)$ & .24 & .44 & .26 \\
\hline Fond Regrets (8) & .27 & .37 & .29 \\
\hline I'll Have No Other (9) & .36 & .31 & .33 \\
\hline \multicolumn{4}{|l|}{$3 / 4$ Meter } \\
\hline The Rabbit and the Turtle ( 8 ) & .30 & .36 & .30 \\
\hline Oberek (7) & .29 & .37 & .30 \\
\hline The Moon (9) & .35 & .30 & .34 \\
\hline In My Dreams (8) & .26 & .42 & .27 \\
\hline Means & .30 & .36 & .30 \\
\hline
\end{tabular}

tour preserving errors is significantly higher when subjects receive tonal markers of phrase endings on Day 1 versus Day 2. At the same time, the frequency of errors due to missing notes significantly decreases. Incompatible accent structures, however, are unaffected by this blocking variable.

\section{Error Analyses at Phrase Ending Points}

In these final analyses of the data, recall performance at phrase ending points was examined. In the first, only the conditions in which phrase ending points were marked by tonic triad members were considered. Here, the recall of four types of pitch intervals were of interest: tonic triad members that actually occurred in a melody; erroneous tonic triad members; nontonic triad members; and missing notes.

As the upper row means of Table 5 illustrate, a main effect for information type occurs $\left[F(3,24)=24.0, M S_{\mathrm{e}}=\right.$ $.283, p<.0012]$ where, overall, recall of actual tonic triad members dominates at phrase ending points. This effect, however, varies across joint accent structure to yield a significant interaction $\left[F(9,72)=13.96, M S_{e}=\right.$ $.029, p<.002$ ]. Within compatible accent structures, tonal markers that originally occurred at phrase endings were recalled with $57 \%$ to $60 \%$ accuracy, and they were the most frequent type of interval produced at these locations. Around $25 \%$ of the time, subjects remembered a tonic triad member at phrase ending points, but it was the wrong one (e.g., producing the dominant instead of the mediant or tonic). The least frequently produced intervals were nontonic triad members and missing notes. This pattern of results is in striking contrast to that found within incompatible accent structures. Here, phrase ending points were more frequently associated with nontonic triad members or missing notes than with intervals identifying a melody's tonality scheme.

Lastly, recall performance was examined for melodies lacking tonic triad members at phrase ending points. The

Table 5

Mean Percent Recall at Phrase Ending Points as a Function of Joint Accent Structure and Phrase Ending Type

\begin{tabular}{|c|c|c|c|c|c|}
\hline \multirow[b]{3}{*}{$\begin{array}{l}\text { Information Recalled } \\
\text { at Phrase Endings }\end{array}$} & \multicolumn{4}{|c|}{ Accent Structures } & \multirow[b]{3}{*}{$M$} \\
\hline & \multicolumn{2}{|c|}{ Compatible } & \multicolumn{2}{|c|}{ Incompatible } & \\
\hline & $\begin{array}{l}\text { 8:4 Ratio } \\
\text { 6:3 Ratio } \\
\end{array}$ & $\begin{array}{l}\text { 8:8 Ratio } \\
\text { 6:6 Ratio } \\
\end{array}$ & $\begin{array}{l}\text { 8:3 Ratio } \\
\text { 6:4 Ratio } \\
\end{array}$ & $\begin{array}{l}\text { 8:6 Ratio } \\
\text { 6:8 Ratio }\end{array}$ & \\
\hline \multicolumn{6}{|c|}{ Phrases Marked by Tonic Triad Intervals } \\
\hline Original tonic triad members & .57 & .60 & .15 & .19 & .38 \\
\hline Erroneous tonic triad members & .24 & 25 & .13 & .17 & .20 \\
\hline Nontonic triad members & .11 & .09 & .33 & .28 & .20 \\
\hline Missing notes & .08 & .06 & .39 & .36 & .22 \\
\hline \multicolumn{6}{|c|}{ Phrases Marked by Nontonic Triad Intervals } \\
\hline Original intervals & .28 & .32 & .23 & .25 & .27 \\
\hline Erroneous intervals & .25 & .22 & .19 & .24 & .23 \\
\hline Tonic triad members & .24 & .26 & .16 & .11 & .19 \\
\hline Missing notes & .23 & .20 & .42 & .40 & .31 \\
\hline
\end{tabular}

Note-Within each condition, the percent recall of different types of pitch information is categorized 
goal here was to determine whether these intervals nevertheless intrude at phrase boundaries. The results are depicted in the lower panel of Table 5.

A main effect for error type $\left[F(3,24)=6.60, M S_{\mathrm{e}}=\right.$ $.05, p<.002]$ reveals that, overall, phrase endings produced a high frequency of missing notes and a low incidence of tonic triad members. These effects, however, varied with joint accent structure $[F(9,72)=17.67$, $\left.M S_{\mathrm{e}}=.004, p<.0004\right]$. Bonferroni comparisons indicated that tonal markers as well as correct intervals were more apt to be recalled within compatible accent structures, whereas missing notes were much more frequent within incompatible ones. The only other effect to emerge from this analysis is an interaction between error type and blocking by day of phrase ending type $[F(3,24)=5.34$, $\left.M S_{\mathrm{e}}=.05, p<.05\right]$. Here, phrase endings were more apt to be associated with correct recall or markers of tonality when this particular set of melodies was presented on Day 2 versus Day 1.

\section{DISCUSSION}

The results of this experiment reveal a set of structural relations important for both the perceptual pickup and subsequent remembering of a tune. At the most general level, all involve the extent to which a melody's temporal accent structure highlights the hierarchical arrangement of melodic structure.

Sequences of notes can display various types of relations, perhaps the most critical of which are movements toward tonal stability and resolution within a tune. In much Western music, these higher level phrases are marked by tonic triad members anchored to the melody's tonality scheme. The present results indicate that recall is most successful when patterns of temporal accentuation coincide with these markers of phrase endings. Error analyses further revealed that these intervals are highly likely to be recalled and that when errors do occur, they involve confusions with other tonic triad members. Only on rare occasions are phrase endings associated with missing notes or other in-key intervals. In contrast, memory is significantly impaired when tonic triad members are either absent or obscured by rhythmic accentuation. This occurs even when temporal accents recur with a fixed periodicity to yield a uniform parsing of melodic structure. Here, the frequency of missing notes and misremembered intervals is quite high at phrase endings, and markers of tonality are much less apt to be retrieved. There is, however, one finding of interest that appears in conditions in which phrase endings are marked by other in-key intervals. When rhythm coincides with melodic phrase structure, tonic triad members are often erroneously remembered at these locations. This suggests that some other type of information serves to outline the melody's underlying organization and that listeners expect these higher order divisions to offer bases of tonal stability. As a whole, this set of results indicates that phrase markers offer effective retrieval cues for the recapitulation of a tune, provided that their presence is attentionally highlighted by temporal accentuation.

A second important determinant of melody recall involves lower order pitch information. In many compositions, contour changes and significant pitch skips both contribute to the hierarchical outline of melodic structure by coinciding with mensural spans and higher order phrases (Berry, 1976; Boltz \& Jones, 1986; Jones, 1987; Monahan $\&$ Carterette, 1985). Thus, sequences of notes within these local periodicities can be grouped on the basis of pitch proximity and a common trajectory of pitch direction (Deutsch \& Feroe, 1981; Dowling \& Harwood, 1986). When these are reinforced by rhythmic structure, they establish an efficient course for perceptual pickup and subsequent remembering. In fact, the most difficult melodies to remember within this experiment were those displaying ill-timed contour changes and/or large pitch skips in the midst of a mensural span. Attending becomes misguided within these structural arrangements, and higher order tonal relations become less apparent. However, pitch changes reinforced by rhythmic accent structure can improve performance by revealing relations among local groupings and their nesting of adjacent notes. This was seen within the conditions of compatible accent structures, even when tonic triad members were absent at phrase ending points. Overall performance was significantly higher relative to incompatible accent conditions, and errors tended to preserve the melody's original contour. This was also true when certain melodic instances displayed pitch changes that precisely coincided with temporal accent structure. As the error analyses indicated, the dynamic profile of contour change was most apt to be lost within incompatible accent structures.

The view that emerges from this overall pattern of results implies a framework in which the acts of perceiving and remembering are linked to a common attentional scheme. A theoretical model recently offered by Jones and Boltz (1989) outlines various ways in which event structure can affect the course of dynamic attending and perceptual pick-up. The basic assumption is that natural events vary along a continuum of structural coherence. Some events, such as music and speech, are highly coherent in that the organization of temporal and nontemporal information coincides with one another to offer a high degree of structural predictability. These events are relatively easy to attentionally track over time, and attending is primarily targeted toward higher level relations within the event's structure. In music, these would typically correspond to the beginnings and ends of melodic phrases, whereas in stories and films, higher level attending might be directed toward shifts in episodes and new idea units. Less coherent events, on the other hand, are characterized by a less predictable structure, which often arises from incompatible temporal/nontemporal relations. The "music" of a novice pianist or the speech of a foreigner learning a new language exemplifies such events. Here, attending is "analytical" in nature, because the apparent lack of internal organization forces attend- 
ing toward details and lower level relations among adjacent items. These effects of event structure on perceptual pickup have been documented for a variety of tasks, including those of perceptual discrimination (Jones et al., 1982; Monahan et al., 1987), relative time judgments (Boltz, 1989c, 1991b; Jones \& Boltz, 1989), and perceptual ratings (Boltz, 1989a, 1989b; Palmer \& Krumhansl, 1987). The results found here suggest that similar processes apply to the act of remembering.

From this perspective, remembering is essentially an act of reperceiving, in that the same structural relations that are used to guide attending over an event's time span are used to recapitulate the event's sequence of items. Joint accent structures offer particularly efficient retrieval schemes for remembering, because lawful relations are maintained among the various levels of structure. In the case of music, meter and the invariance of temporal accentuation pave a dynamic route between the beginning and end of a melody, along which temporal accents illuminate regularly recurrent landmarks in the form of melodic phrase endings. The tonic triad members at these locations offer referents for retrieving lower order relations among adjacent notes, which is often facilitated by local groupings based on similarities of contour change and/or pitch proximity. Unsuccessful retrieval schemes arise from less lawful relations among structural levels and, as seen here, yield response protocols that are much more fragmented. This lack of structural predictability results from ill-timed changes in tonal stability, contour change, or pitch distance, and of these, the obscurity of tonic triad members appears to be the most disruptive to melody recall. This makes sense if remembering involves a top-down process, as is implied by this perspective.

These ideas are consistent with earlier work done by Boltz and Jones (1986), who offered a joint accent hypothesis to predict the success of melody recall. The basic assumption is that performance depends on the ratio relationship of temporal and melodic accents and the degree to which changes in contour and pitch distance regularly recur in time. The present research has empirically confirmed this notion with the recall of tonal music. In addition, the joint accent hypothesis has been extended to address the role of tonality schemes and the use of phrase ending points as referents for recall. The model is also able to specify the types of errors that will occur when such referents are either absent or obscured by rhythmic structure. Lastly, the present set of results dovetail nicely with those of Sloboda and Parker (1985), who also examined recall performance for an unfamiliar set of folk tunes. In that study, an observational technique was used; subjects were asked to reproduce a tune through singing, and response protocols were then examined to determine what kind of information was remembered best. The results showed that recall of meter and phrase structure was quite high, whereas memory for other aspects of a tune (contour, pitch interval distance, etc.) was relatively low. In the present study, similar results were found with a music notation task and an experimental variation of melodic/ temporal phrase structure. A written notation task varies from singing, in that the former requires a greater memory demand and the technique itself may encourage a somewhat more analytic mode of attending. Nevertheless, the level of recall was comparable to that of Sloboda and Parker's study, and the results showed that tonic triad markers were important referents for recall. Further, rhythm variations exerted a major impact on performance, even though reproduction of meter and rhythm was not requested from subjects. Together, both sets of findings imply that a melody's temporal structure establishes a dynamic route for remembering and that anchors of tonality are cognitively salient.

The effects of joint accent structure on remembering are not unique to the realm of music; they can also be found in many other natural events. In another experiment conducted in this laboratory, the effects of rhythm on the recall of visual stories (i.e., films) were examined. As has been outlined in several accounts of story grammar (e.g., Mandler \& Johnson, 1977; Thorndyke, 1977), stories can be described in terms of a hierarchical arrangement of structure in which actions oriented toward a common goal form episodes, which in turn are nested within the story's plot and overarching theme. When stories are depicted as televised movies, the insertion of commercials acts as a type of rhythm to segment the movie into temporal units. In this study, it was found that commercials occurring between episodes led to significantly higher recall and fewer errors of constructive memory than did "ill-timed" commercials occurring within episodes (Boltz, 1991a).

Some research by Robinson (1986) further illustrates the effects of temporal accentuation on recall performance. Robinson suggests that life experiences are organized within higher order temporal phrases defined by one's work calendar. For a student, temporal phrases are marked by the beginnings and ends of semester terms, whereas those for a farmer are marked by the acts of planting, cultivating, and harvest. These markers of activity change serve as effective retrieval schemes, in that the recall of word lists is much higher when category boundaries coincide with temporal referents than when the two are out of phase with one another. In addition, the recall of life experiences from the past year is significantly higher at phrase ending points, even when factors of event salience and frequency are taken into account. Lastly, Linton's (1986) study of autobiographical memory reveals phrases of much longer periodicities. She has found that memories of one's past are organized around temporal landmarks defined by transitions in the major "themes" of life, normally shifts in personal relationships and career objectives.

These sets of findings, taken together, suggest that many events display a hierarchical arrangement of structure in which nested levels of organization are highlighted by patterns of temporal accentuation. From the perspective offered here, joint accent structures not only guide attending over time but also offer cognitive referents from which to recapitulate the event itself. The acts of perceiving and 
remembering are therefore linked to a common attentional scheme, a scheme that can be applied to a wide variety of events within the environment.

\section{REFERENCES}

Benjamin, W. (1984). A theory of musical meter. Music Perception, 1, 355-413.

BERRY, W. (1976). Structural functions in music. Englewood Cliffs, NJ: Prentice-Hall.

BolTz, M. (1985). An expectancy model of judged duration: An ecological perspective. Unpublished doctoral dissertation, Ohio State University.

BoLtz, M. (1989a). Perceiving the end: Effects of tonal relationships on melodic completion. Journal of Experimental Psychology: Human Perception \& Performance, 15, 749-761.

BoLTz, M. (1989b). Rhythm and "good endings"': Effects of temporal structure on tonality judgments. Perception \& Psychophysics, 46, 9-17.

Boltz, M. (1989c). Time judgments of musical endings: Effects of expectancies on the "filled interval effect." Perception \& Psychophysics, 46, 409-418.

BoLtz, M. (1991a). Temporal accent structure and the remembering of filmed narratives. Manuscript submitted for publication.

BolTZ, M. (1991b). Time estimation and attentional perspective. Perception \& Psychophysics, 49, 422-433.

Boltz, M., \& JoNES, M. R. (1986). Does rule recursion make melodies easier to reproduce? If not, what does? Cognitive Psychology, 18, $389-431$

Bower, G., \& SPRINGSton, F. (1970). Pauses as recoding points in letter series. Journal of Experimental Psychology, 83, 421-430.

BoWER, G., \& WINSENZ, D. (1969). Group structure, coding, and memory for digit series. Journal of Experimental Psychology, 80, 1-17.

BUTTERWORTH, B. (1975). Hesitation and semantic planning in speech. Journal of Psycholinguistic Research, 4, 75-87.

Collard, R., \&ovel, D. (1982). Theory of serial patterns production: Tree reversals. Psychological Review, 89, 693-707.

CONE, E. (1968). Music form and musical performance. New York: Norton.

Cuddy, L., Cohen, A., \& Mewhort, D. (1981). Perception of structure in short melodic sequences. Journal of Experimental Psychology: Human Perception \& Performance, 7, 860-883.

Cuddy, L., Cohen, A., \& Muler, J. (1979). Melody recognition: The experimental application of musical rules. Canadian Journal of Psychology, 33, 148-157.

DEUTSCH, D. (1980). The processing of structured and unstructured tonal sequences. Perception \& Psychophysics, 28, 381-389.

DeUTSCH, D., \& FeROE, J. (1981). The internal representation of pitch sequences in tonal music. Psychological Review, 88, 503-522.

DowLING, W. J. (1978). Scale and contour: Two components of a theory of memory for melodies. Psychological Review, 85, 341-354.

Dowling, W. J. (1982). Chroma and interval in melody recognition: Effects of acquiring a tonal scheme. Journal of the Acoustical Society of America, 72, S11 (abstract).

Dowling, W. J., Fujitani, D. (1971). Contour, interval, and pitch recognition in memory for melodies. Joumal of the Acoustical Society of America, 49, 524-531.

Dowling, W. J., HARWOOD, D. (1986). Music cognition. New York: Academic Press.

Dowling, W. J., Lund, K. M.-T., Herrbold, S. (1987). Aiming attention in pitch and time in the perception of interleaved melodies. Perception \& Psychophysics, 41, 642-656.

EDWORTHY, J. (1983). Towards a pitch-contour continuum theory of memory for melodies. In D. Rogers \& J. Sloboda (Eds.), Acquisition of symbolic skills (pp. 263-271). New York: Plenum.

Fritzen, J., \&ohNSON, N. (1969). Definiteness of pattern ending and uniformity of pattern size: Their effect upon learning number sequences. Journal of Verbal Learning \& Verbal Behavior, 8, 575-580.

Gerard, C., AuXIETte, C. (1988). The role of melodic and verbal organization in the reproduction of rhythmic groups by children. Music Perception, 6, 173-192.

Goldman-EISLER, F. (1968). Psycholinguistics: Experiments in spontaneous speech. London: Academic Press.

HALPERN, A., \& Bower, G. (1982). Musical expertise and melodic structure in memory for musical notation. American Journal of Psychology, 95, 31-50.

HANDEL, S. (1973). Temporal segmentation of repeating auditory patterns. Journal of Experimental Psychology, 101, 46-54.

HANDEL, S. (1974). Perceiving melodic and hythmic auditory patterns. Journal of Experimental Psychology, 103, 922-933.

JoNEs, M. R. (1976). Time, our lost dimension: Toward a new theory of perception, attention, and memory. Psychological Review, 83, 323-335.

JONES, M. R. (1981a). Music as a stimulus for psychological motion: Part I. Some determinants of expectancies. Psychomusicology, 1 , 34-51.

JoNEs, M. R. (1981b). Only time can tell: On the topology of mental space and time. Critical Inquiry, 7, 557-576.

JONES, M. R. (1987). Dynamic pattern structure in music: Recent theory and research. Perception \& Psychophysics, 41, 621-634.

Jones, M. R., \& Boltz, M. (1989). Dynamic attending and responses to time. Psychological Review, 96, 459-491

Jones, M. R., BolTz, M., \& KIDD, G. (1982). Controlled attending as a function of melodic and temporal context. Perception \& Psychophysics, 32, 211-218.

Kallman, H. J., Massaro, D. W. (1979). Tone chroma is functional in melody recognition. Perception \& Psychophysics, 26, 32-36.

KIDD, G., Boltz, M., \& JonEs, M. R. (1984). Some effects of rhythmic context on melody recognition. American Journal of Psychology, 97, 153-173.

Kramer, J. (1982). Beginnings and endings in Western art music. Canadian University Music Review, 3, 1-14.

LERDAHL, F., JACKENDOFF, R. (1983). A generative theory of tonal music. Cambridge, MA: MIT Press.

Linton, M. (1986). Ways of searching and the contents of memory. In D. Rubin (Ed.), Autobiographical memory (pp. 50-67). Cambridge, U.K.: Cambridge University Press.

MANDLER, J., JoHnSON, N. (1977). Remembrance of things parsed: Story structure and recall. Cognitive Psychology, 9, 111-151.

MARTIN, J. (1972). Rhythmic (hierarchical) versus serial structure in speech and other behavior. Psychological Review, 79, 487-509.

MEYER, L. (1956). Emotion and meaning in music. Chicago: University of Chicago Press.

Monahan, C. B., \& Carterette, E. C. (1985). Pitch and duration as determinants of musical space. Music Perception, 3, 1-32.

Monahan, C. B., Kendall, R. A., * Carterette, E. C. (1987). The effect of melodic and temporal contour on recognition memory for pitch change. Perception \& Psychophysics, 41, 576-600.

PaLmer, C., KRUMhansL, C. (1987). Independent temporal and pitch structures in determination of musical phrases. Joumal of Experimental Psychology: Human Perception \& Performance, 13, 116-126.

Piston, W. (1978). Harmony (4th ed., revised and expanded by M. DeVoto). New York: Norton.

Povel, D. (1985). Time, rhythms, and tensions: In search of the determinants of rhythmicity. In J. Michon \& J. Jackson (Eds.), Time, mind, and behavior (pp. 215-225). New York: Springer.

RESTLE, F. (1970). Theory of serial pattern learning: Structural trees. Psychological Review, 79, 487-509.

RESTLE, F. (1972). Serial patterns: The role of phrasing. Journal of Experimental Psychology, 92, 385-390.

RESTLE, F., BROWN, E. (1970). Serial pattern learning. Journal of Experimental Psychology, 83, 120-125.

RoBinson, J. (1986). Temporal reference systems and autobiographical memory. In D. Rubin (Ed.), Autobiographical memory (pp. 159188). Cambridge, U.K.: Cambridge University Press.

Rosenbaum, D., Kenny, S., \& Derr, M. (1983). Hierarchical control of rapid movement sequences. Joumal of Experimental Psychology: Human Perception \& Performance, 9, 86-102. 
Simon, H. (1972). Complexity and the representation of patterned sequences of symbols. Psychological Review, 79, 369-382.

SLOBODA, J. (1976). Visual perception of musical notation: Registering pitch symbols in memory. Quarterly Joumal of Experimental Psy. chology, 28, 1-16.

Sloboda, J. (1978). Perception of contour in music reading. Perception, 6, 323-331.

SLOBOdA, J., GRegory, A. (1980). The psychological reality of musical segments. Canadian Journal of Psychology, 34, 274-280

SLOBODA, J., PARKER, D. (1985). Immediate recall of melodies. In P. Howell, I. Cross, \& R. West (Eds.), Musical structure and cognition (pp. 143-167). London: Academic Press.

Thomassen, J. (1982). Melodic accent: Experiments and a tentative model. Journal of the Acoustical Society of America, 71, 1596-1605.

THORNDYKe, P. (1977). Cognitive structures in comprehension and memory of narrative discourse. Cognitive Psychology, 9, 77-110.

TodD, N. (1985). A model of expressive timing in tonal music. Music Perception, 3, 33-58.

Todd, R., Boltz, M., \&ones, M. R. (1989). The MIDILAB auditory research system. Psychomusicology, 8, 83-96.

VITZ, P., ToDD, T. (1967). A model of learning for simple repeating binary patterns. Journal of Experimental Psychology, 75, 108-117.

YESTON, M. (1976). The stratification of musical rhythm. New Haven: Yale University Press.

\section{NOTES}

1. Mathematical rules used in the generation of music have typically derived from group symmetry theory and the set of transformationa rules within the dihedral group of Order 7 .

2. In lieu of musical notation, a singing task was originally considered because this allows one to assess recall for both musicians and nonmusicians, as well as the retrieval of both pitch and timing information. However, a pilot study revealed that such protocols are extremely difficuit to score in that the distance between adjacent intervals as well as the location of missing notes cannot always be reliably determined. Hence a written notation task was used to achieve greater scoring reliability and to determine where missing notes occur (which was important for later error analyses)

3. The original versions of these folk tunes were selected from Folk Songs of Many Peoples, Vol. 1, edited by Florence Hudson Botsford (New York: The Woman's Press, 1921).

(Manuscript received August 6, 1990; revision accepted for publication October 15,1990 .) 